\title{
Effects of Baerveldt Glaucoma Implant Surgery on Corneal Endothelial Cells of Patients with No History of Trabeculectomy
}

This article was published in the following Dove Press journal: Clinical Ophthalmology

\section{Naoki Tojo \\ Atsushi Hayashi \\ Mizuki Hamada (iD)}

Department of Ophthalmology, Graduate School of Medicine and Pharmaceutical Sciences, University of Toyama, Toyama, Japan
Correspondence: Atsushi Hayashi Department of Ophthalmology, Graduate School of Medicine and Pharmaceutical

Sciences, University of Toyama, 2630

Sugitani, Toyama City 930-0194, Japan

Tel +8I-76-434-7363

Fax +8I-76-434-5037

Email ahayashi@med.u-toyama.ac.jp
Purpose: Persistent corneal edema is a serious potential complication of Baerveldt glaucoma implant (BGI) surgery. A trabeculectomy reduces the density of corneal endothelial cells. We investigated the effect of BGI surgery on corneal endothelial cells of patients with no history of trabeculectomy.

Methods: We retrospectively analyzed 85 eyes of 85 patients who underwent BGI surgery and were followed-up for $\geq 12$ months. We used new criteria for surgical failure. We defined persistent corneal edema or needed additional surgery for changing the tube position due to remarkable reduction in corneal endothelial cells as failure. We compared surgical outcomes with new criteria and the rates of corneal endothelial cell density (ECD) loss after BGI surgery between the anterior chamber insertion (AC) group ( $n=23$ ) and vitreous cavity insertion (VC) group $(n=63)$.

Results: The mean pre-operative ECD values of the AC and VC groups were not significantly different at $2309 \pm 498$ and $2204 \pm 556(\mathrm{p}=0.426)$. The ECD reduction rate in the AC group was significantly faster than in the VC group. The mean post-operative IOP values significantly decreased in both groups. However, the VC group's surgical outcomes were significantly better than the AC group's ( $\mathrm{p}=0.0241$ ) with the new criteria.

Conclusion: The mean of ECD did not decrease significantly after BGI surgery in VC group patients with no history of trabeculectomy. BGI surgery insertion to the vitreous cavity was safe and had much less effect on the ECD decrease compared to insertion to the anterior chamber.

Keywords: baerveldt, corneal endothelial cells, anterior chamber, vitreous cavity, glaucoma implant surgery

\section{Introduction}

In Japan, the Baerveldt glaucoma implant (BGI) (Johnson \& Johnson Vision, Santa Ana, CA) was approved for clinical use in 2012. There are three types of BGI devices: one (BGI102-350) was designed to be inserted into the vitreous cavity, and the two others (BGI101-350 and BGI103-250) were designed to be inserted into the anterior chamber. Several research groups compared the outcomes of BGI surgery between insertion into the anterior chamber and insertion into the vitreous cavity, ${ }^{1-3}$ and they each reported that there was no significant difference in the post-operative intraocular pressure (IOP) values between anterior chamber insertion and vitreous cavity insertion. However, other groups reported that anterior chamber insertion decreases the density of corneal endothelial cells in the eye more quickly ${ }^{1,3-5}$. In BGI surgery, the rapid reduction of the density of corneal endothelial cells is one of the serious problems cause persistent corneal edema. ${ }^{6}$ 
BGI surgery has been performed for refractory glaucoma and in cases of an unsuccessful trabeculectomy. ${ }^{7}$ Most of the BGI surgery reports are of patients with a history of trabeculectomy. It is well known that a trabeculectomy decreases the density of corneal endothelial cells. ${ }^{8-10}$ In patients who have undergone both a trabeculectomy and BGI surgery, it is not clear whether the cause of the reduction of the density of corneal endothelial cells was the trabeculectomy or the BGI surgery.

We conducted the present study to investigate the effects of BGI surgery alone on corneal endothelial cells loss. We retrospectively examined the reduction rate of corneal endothelial cell density (ECD) after BGI surgery for patients who had no history of trabeculectomy, and we compared the ECD reduction rate between the anterior chamber insertion (AC) group and vitreous cavity insertion (VC) group. This study has two characteristic points. One is to more purely observe the effects of BGI surgery for ECD loss by excluding patients with a history of trabeculectomy. The other is using new criteria defined persistent corneal edema or needed additional surgery for changing the tube position due to remarkable reduction in corneal endothelial cells as failure.

\section{Subjects and Methods Subjects}

This was a retrospective study. We have no obvious surgical indications for BGI surgery. Surgical indication was decided by two glaucoma specialists (N.T and A.H). We included patients who had undergone BGI surgery at Toyama University Hospital during the period from June 2013 through March 2018 and who were followedup for $>12$ months. We excluded patients who had a history of trabeculectomy (including Ex-Press), laser iridotomy, peripheral iridotomy and keratoplasty. We included the patients who had a history of cataract surgery, trabeculotomy (including Trabecutome, canaloplasty) and vitrectomy. All type of glaucoma was included as primary open-angle glaucoma (POAG), primary angle-closure glaucoma (PACG), secondary glaucoma (SG) (including pseudoexfoliation glaucoma (PEG), uveitic glaucoma and neovascular glaucoma (NVG)). In this study, we divided four glaucoma types as POAG, PEG, NVG and other SG. There was no case of PACG. We identified 85 patients ( 88 eyes) who met these criteria. There were three patients for whom a BGI was implanted in both eyes, and in these cases, we used unilateral data of the eye that was operated earlier. The details of the BGI surgery procedure were as described. ${ }^{1}$
This study was approved by the Institutional Review Board of the University of Toyama (approval no. 23-100) and was performed in accordance with the Declaration of Helsinki. In light of the retrospective nature of this study, the requirement for informed patient consent was waived.

\section{Post-Operative Ophthalmic Examinations}

The items evaluated post-operatively were the IOP, the number of antiglaucoma medications, best-corrected visual acuity (BCVA), and central corneal ECD. In the case of the patients who underwent additional glaucoma surgery, we used only the IOP data before the additional glaucoma surgery. We express the decimal visual acuity (VA), converted to $\log$ MAR visual acuity. In the cases of persistent corneal edema in which the ECD could not be measured, we used the last reliably measured ECD. In the patients who underwent keratoplasty, the subsequent ECD data were excluded after additional keratoplasty. We regularly observed fundus with photos and optical coherent tonometer.

\section{Corneal Endothelial Cells}

We examined the ECD of each patient with a specular microscope (EM-4000, Tomey, Nagoya, Japan) that calculates the ECD value automatically. The ECD values were obtained once, were not an average of multiple measurements. We measured only the central ECD. We measured ECD before surgery and every 6 months after BGI surgery. We defined the ECD reduction rate as the ratio of (the difference pre-operative ECD and post-operative ECD) to the pre-operative $\mathrm{ECD}$, and we compared the $\mathrm{ECD}$ reduction rate between the $\mathrm{AC}$ group and $\mathrm{VC}$ group. We did not include the data of persistent corneal edema or additional surgery conducted to change the position of the inserted shunt tube. In the cases of persistent corneal edema, it was not possible to count corneal endothelial cells. In the cases in which the position of the inserted shunt tube was changed from the anterior chamber to the vitreous cavity, we were unable to evaluate the effect on corneal endothelial cells.

\section{Definition of Surgical Failure}

We used two criteria (Criteria A and Criteria B) of surgical outcomes. Criteria $\mathrm{A}$ is the conventional definition of surgical failure, and Criteria B is taken into account remarkable reduction in corneal endothelial cells.

Criteria $\mathrm{A}$ is meeting one or more of the following criteria: (1) IOP $>21 \mathrm{mmHg}$ or not reduced by $20 \%$ below baseline on two consecutive follow-up visits after 3 months, (2) IOP $\leq 5 \mathrm{mmHg}$ on two consecutive follow- 
up visits after 3 months, (3) reoperation for glaucoma, or (4) phthisis or loss of light perception vision. In this study, we defined a successful BGI surgery as success with or without the need for post-operative glaucoma medications.

Criteria B is meeting one or more of the following two criteria: (1) Persistent corneal edema (in which the ECD could not be measured with the EM-400 specular microscope), or (2) additional surgery was needed to counteract the decreased density of corneal endothelial cells; specifically, cases with a marked decrease of the ECD and cases in which surgery was conducted to change the position of the inserted shunt tube.

As this study was retrospective, there was no clear definition of the surgical indications to change the position of the tube. The decision was made by the attending physician in each case in consideration of the patient's post-operative ECD, the ECD reduction rate, or the position of the tube. We excluded the ECD data that were uncountable due to persistent corneal edema, and we excluded the ECD data of the patients who underwent a tube-position change after their additional surgery.

We investigated the following 9 factors related to surgical outcomes with Criteria A and Criteria B. (1) Age, (2) number of pre-operative glaucoma medications, (3) preoperative IOP, (4) pre-operative ECD, (5) type of glaucoma (NVG, POAG, PEG and SG), (6) unsert position (AC group or VC group), (7) history of cataract surgery, (8) history of trabeculotomy (including Trabecutome or Canaloplasty) and (9) history of pars plana vitrectomy.

\section{Statistical Analysis}

We used the paired $t$-test and Fisher's exact test for comparisons between the AC and VC groups. Wilcoxon's signed-rank test was used for the comparisons of the preoperative and post-operative ECD values. We used multivariate regression analysis for factors influencing the surgical outcomes. The Kaplan-Meier log test was used for the comparison of the success rate. All statistical analyses were performed with the JMP Pro 14 software program (SAS, Cary, NC). Statistical significance was defined at $\mathrm{p}<0.05$.

\section{Results}

\section{Ophthalmic Data and Surgery}

We included 95 eyes in consecutive cases of BGI surgery. Ten cases dropped out within a year. We analyzed 85 eyes of 85 patients: 23 eyes in the AC group, and 62 eyes in the VC group. Table 1 summarizes the pre-operative ophthalmic data: age, pre-operative IOP, the number of glaucoma medications used, follow-up period, pre-operative ECD value, and type of glaucoma. We classified the glaucoma types as primary and secondary, and secondary was further classified as PEG, NVG, and other SG.

In the comparison of the $\mathrm{AC}$ and $\mathrm{VC}$ groups, the parameters that were significantly different were the follow-up period, the percentage of POAG, and the percentage of NVG. The reason for the longer follow-up period in the AC group was that anterior chamber insertion resulted in rapid corneal endothelial cell loss; thereafter, we performed insertion into the vitreous cavity. Insertion into the vitreous cavity requires a vitrectomy. In the subgroup of eyes with NVG, there were many cases that required vitrectomy, and significantly more cases in the VC group. The AC group had significantly higher percentages of POAG patients and patients with a TLO history, for the same reason. These factors created a bias in the patient groups. In VC group, 31 eyes underwent BGI surgery and vitrectomy simultaneously.

\section{Success Rate and Risk Factors for Surgical Failure}

The BGI was inserted successfully in all of the patients. Figure 1 shows the results of the Kaplan-Meier analysis that used Criteria A and Criteria B. The success rates at 5 years after BGI surgery were $85.2 \%$ in Criteria A, $78.9 \%$ in Criteria B. Ten eyes were failures with Criteria A,

Table I The Ophthalmic Data

\begin{tabular}{|l|l|l|l|}
\hline & $\begin{array}{l}\text { AC } \\
\text { (23 Eyes) }\end{array}$ & $\begin{array}{l}\text { VC } \\
\text { (62 Eyes) }\end{array}$ & p-Value \\
\hline Age (yrs) & $64.9 \pm 16.5$ & $67.5 \pm 12.6$ & 0.436 \\
Pre-operative IOP (mmHg) & $30.6 \pm 9.4$ & $32.1 \pm 8.4$ & 0.460 \\
Pre-operative Medications & $3.8 \pm 0.7$ & $3.6 \pm 0.7$ & 0.223 \\
Follow-up period (months) & $42.5 \pm 15.5$ & $31.9 \pm 17.6$ & 0.0126 \\
Pre-operative ECD & $2309 \pm 498$ & $2204 \pm 556$ & 0.426 \\
(cells/mm ${ }^{2}$ ) & & & \\
History of cataract & $18 / 23(78.3 \%)$ & $59 / 62(95.2 \%)$ & 0.0265 \\
History of PPV & $1 / 23(4.4 \%)$ & $32 / 62(51.6 \%)$ & $<0.0001$ \\
History of TLO & $11 / 23(47.8)$ & $12 / 62(19.4 \%)$ & 0.037 \\
POAG & $12 / 65(52.2 \%)$ & $11 / 62(17.7 \%)$ & 0.0004 \\
NVG & $2 / 23(8.7 \%)$ & $30 / 62(48.4 \%)$ & 0.0003 \\
PEG & $4 / 23(17.4 \%)$ & $12 / 62(19.4 \%)$ & 0.836 \\
Other SG & $5 / 23(21.7 \%)$ & $9 / 62(14.5 \%)$ & 0.735 \\
\hline
\end{tabular}

Abbreviations: IOP, intraocular pressure; $E C D$, endothelial cells density; PPV, pars plana vitrectomy; TLO, trabeculotomy; POAG, primary open-angle glaucoma; PEG, pseudoexfoliation glaucoma; SG, secondary glaucoma. 


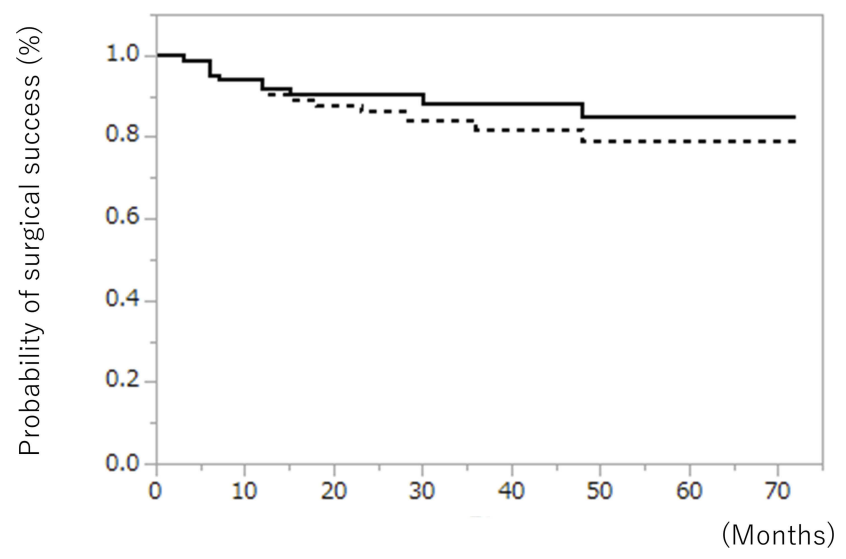

Figure I Results of the Kaplan-Meier analysis that used Criteria A and Criteria B. Solid line: Criteria A. Dotted line: Criteria B.

fourteen eyes were failure with Criteria B. The reasons for failure with Criteria A were the need for additional glaucoma surgery in five eyes, IOP $>21 \mathrm{mmHg}$ in one eye and no light sensation in four eyes. The cases who resulted in persistent corneal edema were three eyes and required additional surgery to change the tube position due were four eyes.

We investigated factors that influencing surgical outcomes with Criteria A and Criteria B using multivariate analysis. There was no significant influencing factor with Criteria A (Table 2). There was no case of surgical failure in PEG patients or SG patients with Criteria A. With Criteria B, insertion position significantly influenced for surgical outcomes (Table 3).

Table 2 Results of A Multivariate Analysis of Factors Associated with Surgical Outcomes with Criteria A

\begin{tabular}{|l|l|l|l|l|}
\hline Factors & $\begin{array}{l}\text { Odds } \\
\text { Ratio }\end{array}$ & $\begin{array}{l}\text { CI Lower } \\
95 \%\end{array}$ & $\begin{array}{l}\text { CI Upper } \\
95 \%\end{array}$ & P Value \\
\hline Age & 1.021 & 0.9461 & 1.108 & 0.6214 \\
Premedications & 1.138 & 0.337 & 3.849 & 0.933 \\
Pre-IOP & 1.0004 & 0.998 & 1.002 & 0.126 \\
Pre-ECD & 1.083 & 0.973 & 1.206 & 0.679 \\
$\begin{array}{l}\text { Type of glaucoma } \\
\text { (NVG) }\end{array}$ & 6.734 & 0.254 & 178.729 & 0.254 \\
$\begin{array}{l}\text { Type of glaucoma } \\
\text { (POAG) }\end{array}$ & 1.426 & 0.0948 & 21.46 & 0.798 \\
Insert position (AC & 0.0993 & 0.00532 & 1.855 & 0.122 \\
or Vit) & & & & 0.302 \\
History of cataract & 0.203 & 0.00988 & 1.179 & 0.687 \\
History of TLO & 0.682 & 0.106 & 4.393 & 0.705 \\
History of PPV & 0.618 & 0.0511 & 7.474 & \\
\hline
\end{tabular}

Abbreviations: $\mathrm{Cl}$, confidence interval; IOP, intraocular pressure; $\mathrm{ECD}$, endothelial cells density; NVG, neo-vascular glaucoma; POAG, primary open-angle glaucoma; AC, anterior chamber; VC, vitreous cavity; TLO, trabeculotomy; PPV, pars plana vitrectomy.
Table 3 Results of a Multivariate Analysis of Factors Associated with Surgical Outcomes with Criteria B

\begin{tabular}{|c|c|c|c|c|}
\hline Factors & $\begin{array}{l}\text { Odds } \\
\text { Ratio }\end{array}$ & $\begin{array}{l}\text { Cl Lower } \\
95 \%\end{array}$ & $\begin{array}{l}\text { Cl Upper } \\
95 \%\end{array}$ & $P$ Value \\
\hline Age & 0.98 & 0.909 & 1.057 & 0.596 \\
\hline Premedications & 1.184 & 0.361 & 3.889 & 0.777 \\
\hline Pre-IOP & 1 & 0.998 & 1.001 & 0.178 \\
\hline Pre-ECD & 1.067 & 0.968 & 1.177 & 0.891 \\
\hline $\begin{array}{l}\text { Type of glaucoma } \\
\text { (NVG) }\end{array}$ & 5.274 & 0.314 & 88.664 & 0.206 \\
\hline $\begin{array}{l}\text { Type of glaucoma } \\
\text { (POAG) }\end{array}$ & 0.244 & 0.0329 & 14.258 & 0.244 \\
\hline $\begin{array}{l}\text { Type of glaucoma } \\
\text { (PEG) }\end{array}$ & 0.685 & 0.0329 & 14.258 & 0.807 \\
\hline $\begin{array}{l}\text { Type of glaucoma } \\
\text { (SG) }\end{array}$ & 1.664 & 0.334 & 6.537 & 0.502 \\
\hline $\begin{array}{l}\text { Insert position (AC } \\
\text { or } V C \text { ) }\end{array}$ & 0.0316 & 0.00998 & 2.25 & 0.0086 \\
\hline History of cataract & 0.15 & 0.00998 & 2.251 & 0.17 \\
\hline History of TLO & 0.657 & 0.0995 & 4.333 & 0.662 \\
\hline History of PPV & 1.449 & 0.181 & 11.57 & 0.727 \\
\hline
\end{tabular}

Abbreviations: $\mathrm{Cl}$, confidence interval; IOP, intraocular pressure; $\mathrm{ECD}$, endothelial cells density; NVG, neo-vascular glaucoma; POAG, primary open-angle glaucoma; PEG, pseudo-exfoliation glaucoma; SG, other secondary glaucoma; AC, anterior chamber; VC, vitreous cavity; TLO, trabeculotomy; PPV, pars plana vitrectomy.

\section{Post-Operative IOP and Glaucoma Medications}

Table 4 shows the post-operative IOP values and the number of post-operative glaucoma medications used in the AC and VC groups. In both groups, the mean post-operative IOPs were significantly decreased compared to the pre-operative IOPs. After 1 year, the mean IOP in the VC group was significantly decreased compared to the AC group $(p=0.00323)$. The mean number of glaucoma medications was not significantly different between the two groups at any time point.

\section{ECD Reduction Rate}

The mean pre-operative ECD values were $2309 \pm 498$ in the AC group and $2204 \pm 556$ in the VC group, and did not differ significantly $(\mathrm{p}=0.426)$. Table 5 provides the mean post-operative ECD in the AC group. At 3 and 4 years after BGI surgery, the mean ECD was significantly reduced from the pre-operative ECD. Table 6 shows the mean post-operative ECD in the VC group. At all time points, the mean post-operative ECD was not significantly reduced from the pre-operative ECD.

The results of the comparison of the ECD reduction rate between the AC and VC groups are summarized in Table 7. 
Table 4 The Post-Operative IOP Value and Number of Glaucoma Medications

\begin{tabular}{|l|l|l|l|l|l|l|}
\hline \multirow{2}{*}{} & \multicolumn{2}{l}{ AC $(\mathbf{n})$} & \multicolumn{2}{l|}{ VC $(\mathbf{n})$} & \multicolumn{2}{l|}{ p-Value } \\
\cline { 2 - 7 } & IOP $(\mathbf{m m H g})$ & Medications & IOP $(\mathbf{m m H g})$ & Medications & IOP & Medications \\
\hline Pre-operative & $30.6 \pm 9.4(23)$ & $3.7 \pm 0.8(23)$ & $32.1 \pm 8.4(62)$ & $3.6 \pm 0.7(62)$ & 0.460 & 0.223 \\
I year & $12.5 \pm 4.0(23)$ & $2.5 \pm 1.8(22)$ & $10.7 \pm 3.8(62)$ & $2.2 \pm 1.6(62)$ & 0.0675 & 0.411 \\
2 years & $13.7 \pm 4.1(22)$ & $2.7 \pm 1.5(22)$ & $11.3 \pm 3.6(47)$ & $2.2 \pm 1.5(47)$ & 0.0350 & 0.239 \\
3 years & $12.0 \pm 4.9(17)$ & $2.4 \pm 1.7(17)$ & $11.6 \pm 3.7(28)$ & $1.9 \pm 1.7(28)$ & 0.708 & 0.388 \\
4 years & $11.9 \pm 4.2(14)$ & $2.2 \pm 1.4(14)$ & $12.6 \pm 3.6(18)$ & $2.3 \pm 1.8(18)$ & 0.654 & 0.840 \\
5 years & $11.4 \pm 5.6(8)$ & $2.1 \pm 2.0(8)$ & $11.4 \pm 3.7(10)$ & $2.5 \pm 1.4(10)$ & 0.991 & 0.593 \\
\hline
\end{tabular}

Abbreviations: AC, anterior chamber; VC, vitreous cavity; IOP, intraocular pressure.

Table 5 The Mean Post-Operative ECD Value in the AC Group

\begin{tabular}{|l|l|l|l|}
\hline $\begin{array}{l}\left(\text { Cells } / \mathbf{m m}^{2}\right) \\
(n)\end{array}$ & $\begin{array}{l}\text { Pre-Operative } \\
\text { ECD }\end{array}$ & $\begin{array}{l}\text { Post-Operative } \\
\text { ECD }\end{array}$ & p-Value \\
\hline I year (22) & $2310 \pm 498$ & $2136 \pm 686$ & 0.681 \\
2 years (19) & $2424 \pm 418$ & $2155 \pm 587$ & 0.164 \\
3 years (16) & $2412 \pm 453$ & $1922 \pm 609$ & 0.0159 \\
4 years (13) & $2388 \pm 506$ & $1810 \pm 627$ & 0.0183 \\
5 years (7) & $2297 \pm 564$ & $1408 \pm 794$ & 0.0639 \\
\hline
\end{tabular}

Abbreviation: $E C D$, endothelial cells density.

Table 6 The Mean of Post-Operative ECD Value in the VC Group

\begin{tabular}{|l|l|l|l|}
\hline $\begin{array}{l}\left(\text { Cells } / \mathbf{m m}^{2}\right) \\
(\mathbf{n})\end{array}$ & $\begin{array}{l}\text { Pre-Operative } \\
\text { ECD }\end{array}$ & $\begin{array}{l}\text { Post-Operative } \\
\text { IOP }\end{array}$ & p-Value \\
\hline I year (62) & $2207 \pm 582$ & $2203 \pm 556$ & 0.842 \\
2 years (45) & $2259 \pm 478$ & $2297 \pm 493$ & 0.455 \\
3 years (27) & $2292 \pm 431$ & $2196 \pm 431$ & 0.307 \\
4 years (I8) & $2348 \pm 510$ & $2254 \pm 472$ & 0.389 \\
5 years (10) & $2272 \pm 546$ & $2212 \pm 559$ & 0.850 \\
\hline
\end{tabular}

Abbreviation: ECD, endothelial cells density

Table 7 Comparison of the Mean of Post-Operative ECD Reduction Rates in the AC and VC Groups

\begin{tabular}{|l|l|l|l|}
\hline & AC Group (n) & VC Group (n) & P Value \\
\hline I year & $93.1 \pm 19.7 \%(22)$ & $100.8 \pm 13.5 \%(62)$ & 0.0456 \\
2 years & $89.1 \pm 21.3 \%(19)$ & $97.8 \pm 12.1 \%(45)$ & 0.0431 \\
3 years & $80.1 \pm 22.8 \%(16)$ & $96.2 \pm 10.0 \%(27)$ & 0.0025 \\
4 years & $76.8 \pm 22.6 \%(13)$ & $96.6 \pm 9.3 \%(17)$ & 0.0027 \\
5 years & $62.8 \pm 32.2 \%(7)$ & $97.4 \pm 9.1 \%(11)$ & 0.0053 \\
\hline
\end{tabular}

Abbreviations: AC, anterior chamber; VC, vitreous cavity; ECD, endothelial cells density.

The mean ECD reduction rate was significantly decreased in the $\mathrm{AC}$ group at all time points. The ECD reduction rate in the $\mathrm{AV}$ group decreased gradually, whereas the corresponding rate in the $\mathrm{VC}$ group hardly changed.

\section{Comparison Surgical Outcomes Between AC Group and VD group}

Figure 2 shows the results of the Kaplan-Meier analysis with Criteria A of surgical success for the $\mathrm{AC}$ and $\mathrm{VC}$ groups, compared with the log-rank test. The success rates at 5 years after BGI surgery were not significantly different between the groups: $81.3 \%$ in the AC group and $86.2 \%$ in the VC group $(\mathrm{p}=0.516)$. With Criteria $\mathrm{A}$, four eyes were failures in the $\mathrm{AC}$ group and six eyes were failures in the $\mathrm{VC}$ group. The reasons for failure in the $\mathrm{AC}$ group were the need for additional glaucoma surgery in three eyes and no light sensation in one eye. In the VC group, the reasons for failure were the need for additional glaucoma surgery in two eyes, IOP $>21 \mathrm{mmHg}$ in one eye, and no light sensation in three eyes. All six of the failure eyes in the VC group were in the NVG subgroup.

Figure 3 illustrates the Kaplan-Meier curves obtained with Criteria B. The success rate at 5 years after BGI surgery was $63.1 \%$ in the $\mathrm{AC}$ group and significantly better at $86.2 \%$ in the $\mathrm{VC}$ group $(\mathrm{p}=0.0241)$. In the $\mathrm{AC}$ group, there were three eyes with persistent corneal edema, and four eyes requiring additional surgery to change the tube position. In the VC group, one eye had persistent corneal edema, and none of the 65 eyes required additional surgery to change the tube position.

\section{Discussion}

We have reported that the ECD reduction rate in AC eyes was faster than that in $\mathrm{VC}$ eyes. ${ }^{1}$ As a characteristic of the present study, we defined a remarkable reduction in the density of corneal endothelial cells as a failure after BGI surgery. The reason for this result is that persistent corneal edema, which is one of the most severe complications of BGI due to the loss of corneal endothelial cells, results in severe visual loss. The reported rate of persistent corneal edema after BGI surgery is $5.6-17.5 \% .^{6,7}$ An important 


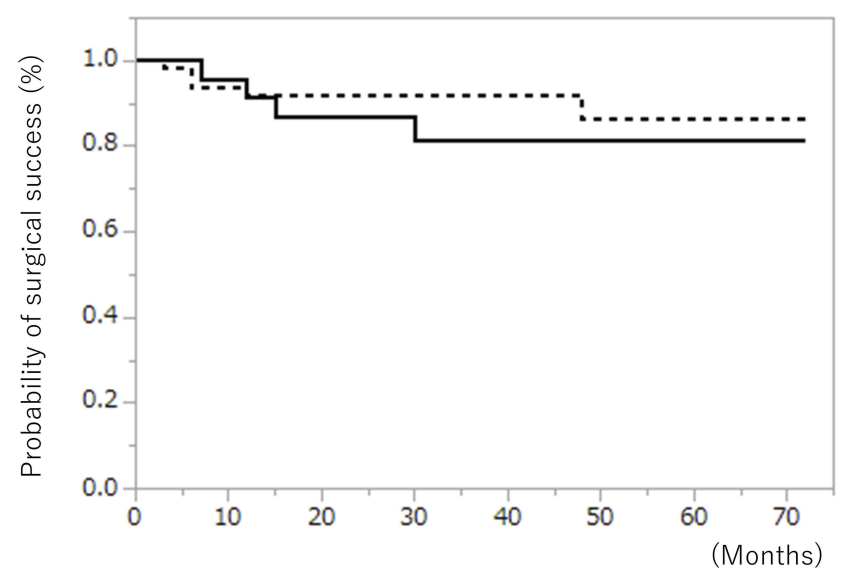

Figure 2 Comparison of surgical outcomes between the AC group and VC group with Criteria A. Solid line: AC group. Dotted line: VC group. No significant difference $(p=0.516)$

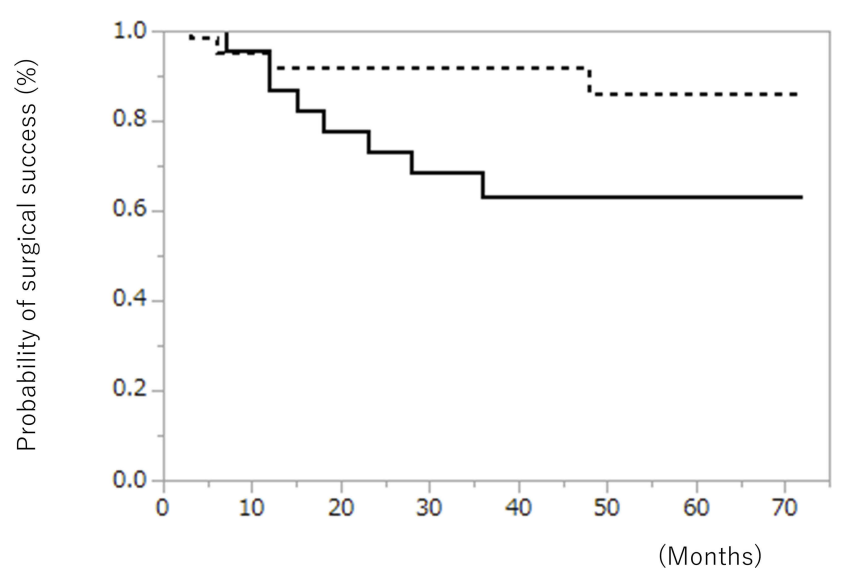

Figure 3 Comparison of surgical outcomes between the AC group and VC group with Criteria B. Significantly better surgical outcomes were achieved in the VC group vs the $A C$ group ( $P=0.024$ I, log-rank test). Solid line: $A C$ group. Dotted line: VC group.

aspect of the present study is that we excluded patients who had undergone a trabeculectomy. By doing so, we were able to investigate the effects of BGI surgery on corneal endothelial cells more purely.

Some studies were reported that there was no significant difference in surgical outcomes between AC group and VC group. ${ }^{2,7}$ In our study, there was no significant difference with Criteria A. However, using Criteria B that we defined newly, we found that anterior chamber insertion an influencing factor for surgical outcomes.

Several research groups have considered the causes of corneal endothelial cell loss due to trabeculectomy. The mean of ECD decreases at an average rate of approx. $0.6 \%$ per year for normal adults, whereas in patients underwent trabeculectomy were about $10 \%$ per year. ${ }^{9-11}$ The reasons rapid corneal endothelial cell loss due to trabeculectomy were toxic effects of mitomycin-C (MMC) or peripheral iridotomy. ${ }^{12,13}$ Ex-Press surgery does not need a peripheral iridectomy. Regarding Ex-Press, there are reports that ECD significantly decreases and not significantly decreases. ${ }^{8,14,15}$ We reported a case in which the insertion of an Ex-Press though cornea into anterior chamber quickly decreased the ECD and resulted in bullous keratopathy. ${ }^{16}$ The reduction of the ECD might depend on the insertion position of the Ex-Press. The proper insertion into the trabecular meshwork might not result in a decrease in the ECD.

In the present study, we included patients with a history of cataract surgery, trabeculotomy, or vitrectomy. It was reported that cataract surgery decreased the ECD by 6.$51-9.75 \%$ ECD. ${ }^{17,18}$ Kasahara et al observed that the use of a trabectome decreased the mean ECD from $2464 \pm 469$ to $2344 \pm 480$, which was not a significant change. ${ }^{19}$ The insertion of a BGI into the vitreous cavity requires a vitrectomy. Emo et al reported that pars plana vitrectomy (PPV) did not significantly decrease the ECD at 3 months post-operatively (2.4\%). PPV plus cataract surgery significantly decreased ECD at 3 months post-operatively $(9.5 \%) .^{20}$

PEG patients are known to exhibit a rapid loss of ECD. ${ }^{9,21-23}$ The reason for this remains unclear. In the present study's investigation of an $\mathrm{AC}$ group and $\mathrm{VC}$ group, we compared the ECD reduction rate between the patients with POAG and those with PE glaucoma at 1 year, and we observed that PE glaucoma did not significantly decrease the ECD faster than the POAG type of glaucoma (AC group, $\mathrm{p}=0.669$; $\mathrm{VC}$ group, $\mathrm{p}=0.525$ ). This result could be due to the number of patients, which was statistically too small. Further studies of larger numbers of patients are needed to determine which type of glaucoma decreases the ECD faster.

Since we excluded patients who had undergone a trabeculectomy from this study, the main cause of the rapid decrease in the ECD was tube insertion into the anterior chamber. As a solution for this decrease in 4 eyes, we performed an additional surgery which repositioned the tube from the anterior chamber to the vitreous cavity. Joos et al reported that the repositioning of an anterior chamber Baerveldt shunt tube into the vitreous cavity is a viable option for resolving recalcitrant tuberelated anterior segment complications. ${ }^{24}$ It will be necessary to observe the change in the ECD reduction rate over the long term after such reposition surgery. 
We considered several explanations for the rapid reduction of endothelial cell density in cases of anterior chamber insertion. First, a tube inserted in the anterior chamber can move with eye movements, and it can directly touch corneal endothelial cells. Law et al reported that the inserted shunt tube moved in the anterior chamber with eye movement. ${ }^{25}$ A second possible explanation is that the abnormal aqueous humor flow could exit the anterior chamber without enough nutrition for the corneal endothelial cells. Freedman and Iserovich proposed that abnormal aqueous humor might contribute to corneal endothelial cell loss. ${ }^{26}$ Third, the inflammatory cytokines due to a shunt tube might affect the corneal endothelial cells. A shunt tube is made of silicon, and Casini et al reported that a foreign body might induce inflammatory cytokines that damage corneal endothelial cells. ${ }^{8}$ A fourth possible explanation for the rapid reduction of endothelial cell density in cases of anterior chamber insertion is that insertion of the tube into the anterior chamber could create peripheral anterior synechia (PAS). Hau et al reported that PAS is a factor associated with rapid ECD reduction. ${ }^{27}$

Our study has some limitations. It is a retrospective, biased study. We did not make a clear definition regarding whether the shunt tube was inserted into the anterior chamber or the vitreous cavity. The two patient groups (AC and VC) had significantly different types of glaucoma, and the ECD reduction rate could depend on or be affected by the type of glaucoma. In general, it is well known that peripheral anterior synechia (PAS) make progressive endothelial cells loss. ${ }^{27}$ In NVG which was significantly more in the VC group, it was expected that the mean of ECD would decrease earlier due to the formation of PAS. However, the ECD decrease ratio in $\mathrm{VC}$ group was significantly slower than in the AC group. From our multivariate analysis, type of glaucoma was not significantly affected by surgical outcomes.

We also included patients who had undergone cataract surgery or trabeculotomy. These surgeries affected corneal endothelial cells loss. Although it is desirable not to include cases that have undergone these operations, BGI surgery was often undergone for refractory glaucoma, and many cases have undergone multiple surgery. We did not make a clear definition for replacing from anterior chamber to vitreous cavity. In this way, because the subjects are different, it might be difficult to simply compare between $\mathrm{AC}$ group and $\mathrm{VC}$ group.

Another limitation is that we measured the ECD only once at the central cornea. The measurement site of the ECD at the central cornea was not exactly the same site in all cases, and the value of the ECD might be different for each measurement. In most of our cases, the pre-operative IOP value was very high; therefore, the effect of corneal edema due to high IOP might make it difficult to determine the ECD. It was odd that the ECD reduction rate exceeded $100 \%$ in the VC group at 1 year after surgery. The ECD reduction rate might have been underestimated, because we excluded the cases that resulted in bullous keratopathy and patients who underwent an additional tube-position change surgery due to rapid ECD reduction.

In conclusion, inserting a BGI into the vitreous cavity did not significantly decrease the ECD of patients with no history of trabeculectomy. We speculate that inserting the shunt tube into the vitreous cavity could decrease the cases of persistent corneal edema.

\section{Ethical Approval}

All procedures performed in studies involving human participants were in accordance with the ethical standards of the institutional and/or national research committee and with the 1964 Helsinki Declaration and its later amendments or comparable ethical standards. This study was approved by the Institutional Review Board of the University of Toyama (approval no. 23-100). The authors declare that they ensure confidentiality of patient data.

\section{Funding}

No funding was received for this research.

\section{Disclosure}

The authors declare that they have no affiliations with or involvement in any organization or entity with any financial interest (such as honoraria; educational grants; participation in speakers' bureaus; membership, employment, consultancies, stock ownership, or other equity interest; and expert testimony or patent-licensing arrangements), or nonfinancial interest (such as personal or professional relationships, affiliations, knowledge or beliefs) in the subject matter or materials discussed in this manuscript.

\section{References}

1. Tojo N, Hayashi A, Consolvo-Ueda T, Yanagisawa S. Baerveldt surgery outcomes: anterior chamber insertion versus vitreous cavity insertion. Graefes Arch Clin Exp Ophthalmol. 2018;256:2191-2200. doi:10.1007/s00417-018-4116-4

2. Qin VL, Kaleem M, Conti FF, et al Long-term clinical outcomes of pars plana versus anterior chamber placement of glaucoma implant tubes. J Glaucoma. 2018;27:440-444. doi:10.1097/IJG.00000000000 00931 
3. Tan AN, Webers CA, Berendschot TT, et al Corneal endothelial cell loss after Baerveldt glaucoma drainage device implantation in the anterior chamber. Acta Ophthalmol. 2017;95:91-96. doi:10.1111/aos.13161

4. Iwasaki K, Arimura S, Takihara Y, Takamura Y, Inatani M. Prospective cohort study of corneal endothelial cell loss after Baerveldt glaucoma implantation. PLoS One. 2018;13:e0201342. doi:10.1371/journal.pone. 0201342

5. Rososinski A, Wechsler D, Grigg J. Retrospective review of pars plana versus anterior chamber placement of Baerveldt glaucoma drainage device. J Glaucoma. 2015;24:95-99. doi:10.1097/IJG.0b013e31829d9 be 2

6. Gedde SJ, Herndon LW, Brandt JD, Budenz DL, Feuer WJ, Schiffman JC. Surgical complications in the Tube Versus Trabeculectomy Study during the first year of follow-up. Am J Ophthalmol. 2007;143:23-31. doi:10.1016/j.ajo.2006.07.022

7. Campagnoli TR, Kim SS, Smiddy WE, et al Combined pars plana vitrectomy and Baerveldt glaucoma implant placement for refractory glaucoma. Int J Ophthalmol. 2015;8:916-921. doi:10.3980/j.issn.22223959.2015.05.11

8. Casini G, Loiudice P, Pellegrini M, et al Trabeculectomy versus Ex-Press shunt versus Ahmed valve implant: short-term effects on corneal endothelial cells. Am J Ophthalmol. 2015;160:1185-1190 e1181. doi:10.1016/j.ajo.2015.08.022

9. Higashide T, Nishino T, Sakaguchi K, Yamada Y, Sugiyama K. Determinants of corneal endothelial cell loss after trabeculectomy with mitomycin C. J Glaucoma. 2019;28:61-67. doi:10.1097/ IJG.0000000000001108

10. Storr-Paulsen T, Norregaard JC, Ahmed S, Storr-Paulsen A. Corneal endothelial cell loss after mitomycin C-augmented trabeculectomy. J Glaucoma. 2008;17:654-657. doi:10.1097/IJG.0b013e3181659e56

11. Bourne WM, Nelson LR, Hodge DO. Central corneal endothelial cell changes over a ten-year period. Invest Ophthalmol Vis Sci. 1997;38:779-782.

12. Nuyts RM, Pels E, Greve EL. The effects of 5-fluorouracil and mitomycin $\mathrm{C}$ on the corneal endothelium. Curr Eye Res. 1992;11:565-570. doi:10.3109/02713689209001812

13. Lim LS, Ho CL, Ang LP, Aung T, Tan DT. Inferior corneal decompensation following laser peripheral iridotomy in the superior iris. $\mathrm{Am}$ J Ophthalmol. 2006;142:166-168. doi:10.1016/j.ajo.2006.01.070

14. Ishida K, Moroto N, Murata K, Yamamoto T. Effect of glaucoma implant surgery on intraocular pressure reduction, flare count, anterior chamber depth, and corneal endothelium in primary open-angle glaucoma. Jpn J Ophthalmol. 2017;61:334-346. doi:10.1007/s10384017-0512-2

15. Omatsu S, Hirooka K, Nitta E, Ukegawa K. Changes in corneal endothelial cells after trabeculectomy and Ex-Press shunt: 2-year follow-up. BMC Ophthalmol. 2018;18:243. doi:10.1186/s12886-018-0913-0
16. Tojo N, Hayashi A, Miyakoshi A. Corneal decompensation following filtering surgery with the Ex-PRESS ${ }^{\circledR}$ mini glaucoma shunt device. Clin Ophthalmol. 2015;9:499-502. doi:10.2147/OPTH.S81050

17. Bourne RR, Minassian DC, Dart JK, Rosen P, Kaushal S, Wingate N. Effect of cataract surgery on the corneal endothelium: modern phacoemulsification compared with extracapsular cataract surgery. Ophthalmology. 2004;111:679-685. doi:10.1016/j.ophtha.2003.07.015

18. Mencucci R, Ponchietti C, Virgili G, Giansanti F, Menchini U. Corneal endothelial damage after cataract surgery: microincision versus standard technique. $J$ Cataract Refract Surg. 2006;32:1351-1354. doi:10.1016/j.jcrs.2006.02.070

19. Kasahara M, Shoji N, Matsumura K. The influence of trabectome surgery on corneal endothelial cells. J Glaucoma. 2019;28:150-153. doi:10.1097/IJG.0000000000001128

20. Eom Y, Kim SW, Ahn J, Kim JT, Huh K. Comparison of cornea endothelial cell counts after combined phacovitrectomy versus pars plana vitrectomy with fragmentation. Graefes Arch Clin Exp Ophthalmol. 2013;251:2187-2193. doi:10.1007/s00417-013-2440-2

21. Quiroga L, Lansingh VC, Samudio M, Pena FY, Carter MJ. Characteristics of the corneal endothelium and pseudoexfoliation syndrome in patients with senile cataract. Clin Exp Ophthalmol. 2010;38:449-455. doi:10.1111/j.1442-9071.2010.02313.x

22. Ostern AE, Drolsum L. Corneal endothelial cells 6-7 years following cataract surgery in patients with pseudoexfoliation syndrome. Acta Ophthalmol. 2012;90:408-411. doi:10.1111/j.1755-3768.2010.02012.x

23. Wang M, Sun W, Ying L, Dong XG. Corneal endothelial cell density and morphology in Chinese patients with pseudoexfoliation syndrome. Int $J$ Ophthalmol. 2012;5:186-189. doi:10.3980/j. issn.2222-3959.2012.02.14

24. Joos KM, Laviña AM, Tawansy KA, Agarwal A. Posterior repositioning of glaucoma implants for anterior segment complications. Ophthalmology. 2001;108:279-284. doi:10.1016/S0161-6420(00)00521-2

25. Law SK, Coleman AL, Caprioli J. Dynamic tube movement of Ahmed glaucoma valve. $J$ Glaucoma. 2009;18:628-631. doi:10.1097/IJG.0b013e3181996f33

26. Freedman J, Iserovich P. Pro-inflammatory cytokines in glaucomatous aqueous and encysted molteno implant blebs and their relationship to pressure. Invest Ophthalmol Vis Sci. 2013;54:4851-4855. doi:10.1167/iovs.13-12274

27. Hau S, Scott A, Bunce C, Barton K. Corneal endothelial morphology in eyes implanted with anterior chamber aqueous shunts. Cornea. 2011;30:50-55. doi:10.1097/ICO.0b013e3181e16d7d
Clinical Ophthalmology

\section{Publish your work in this journal}

Clinical Ophthalmology is an international, peer-reviewed journal covering all subspecialties within ophthalmology. Key topics include: Optometry; Visual science; Pharmacology and drug therapy in eye diseases; Basic Sciences; Primary and Secondary eye care; Patient Safety and Quality of Care Improvements. This journal is indexed on PubMed
Central and CAS, and is the official journal of The Society of Clinical Ophthalmology (SCO). The manuscript management system is completely online and includes a very quick and fair peer-review system, which is all easy to use. Visit http://www.dovepress.com/ testimonials.php to read real quotes from published authors.

\section{Dovepress}

